\title{
Nanaa: \\ o corpo como lugar de nominação pessoal
}

Fabio de Sousa Lima ${ }^{1}$

Instituto Federal de Roraima

Danielle dos Santos Pereira Lima ${ }^{2}$ Universidade Federal de Roraima

Olendina de Carvalho Cavalcante 3

Universidade Federal de Roraima

Resumo: Este artigo discute alguns traços da complexa rede de nominação pessoal Wapichana, a qual assenta-se no processo de construção social do corpo. Nesse sentido, toma-se como polo das discussões a atribuição de nomes designativos e autodesignativos indígenas, processo comum nas terras baixas amazônicas, que repercute na noção de corpo e pessoa. Trata-se de uma pesquisa etnográfica cujos resultados demonstram que o nome cultural que o Wapichana porta presume a existência de uma alma-nome ou um segundo corpo.

Palavras-chave: Wapichana; nome; corpo; pessoa.

${ }^{1}$ Professor de História do Instituto Federal de Roraima (IFRR), mestre em Antropologia Social pela Universidade Federal de Roraima (UFRR).

2 Mestre em Letras Literatura pela Universidade Federal de Roraima (UFRR).

3 Doutora em Antropologia Social pela Universidade Estadual de Campinas (UNICAMP), professora associada do mestrado de Antropologia Social da Universidade Federal de Roraima (UFRR). 
Nanaa:

the body as a place of personal nomination

\begin{abstract}
This article discusses some features of the complex Wapishana personal naming network, which is based on the social construction process of the body. In this sense, the pole of the discussions is the attribution of indigenous designative and self-designating names, a common process in the Amazonian lowlands, which has repercussions on the notion of body and person. It is an ethnographic research whose results demonstrate that the cultural name that the Wapishana port presumes the existence of a soul-name or a second body.
\end{abstract}

Keywords: Wapishana; name; body; person.

Nanaa: el cuerpo como lugar de nominación personal

Resumen: Este artículo analiza algunas características de la compleja red de nombres personales de Wapichana, que se basa en el proceso de construcción social del cuerpo. En este sentido, el polo de las discusiones es la atribución de nombres autodenominados y designados por los indígenas, un proceso común en las tierras bajas de la Amazonía, que repercute en la noción de cuerpo y persona. Es una investigación etnográfica cuyos resultados demuestran que el nombre cultural que lleva el Wapichana presupone la existencia de un nombre de alma o un segundo cuerpo.

Palabras clave: Wapichana; nombre; cuerpo; persona. 
$\mathrm{E}$ ste artigo traz uma reflexão sobre as formas de nominação pessoal Wapichana as quais pressupõem estratégias de autorreconhecimento presentes entre os Wapichana povos indígenas das Terras Baixas da América do Sul4. Na onomástica da Terras Baixas, chamam-se nomes designativos os etnônimos, isto é, as nominações atribuídas aos indígenas por terceiros; por seu turno, quando se fala em nomes autodesignativos presumem-se aquelas formas nominativas que os nativos atribuem a si.

No caso dos Wapichana, eles aparecem em estudos de campos distintos do conhecimento, como Linguística, Antropologia, Literatura Comparada e outros, quando o tema é a noção de pessoa: Farage (1997), com refino poético, mostrou como os Wapichana elaboraram a noção de pessoa pela palavra em ato e práticas retóricas; já Carneiro (2008) pôs em paralelo a noção de pessoa e o uso de topônimos; Tempesta (2004) expôs como, para os Wapichana, corpos não nascem prontos e, muito próximo do que acontece em outras cosmologias amazônicas, como os Desana, acredita-se que a possibilidade de passagens entre os planos de existência humano e não humano faz da humanidade uma questão de perspectiva.

\section{O povo Wapichana e aldeia Malacacheta}

Os Wapichana são um povo indígena que, em território brasileiro, situam-se entre os rios Uraricoera e Tacutu, Roraima. Na Guiana (inglesa), habitam entre os rios Tacutu, Rupununi e Kwitaro. Os Wapichana que vivem no lado brasileiro experimentam uma situação de bilinguismo ou multilinguismo, ora falam Wapichana ora português, ora inglês.

As terras da aldeia Malacacheta no início do século XX pertenciam ao fazendeiro Sizenando Diniz e a esposa Ermelinda do Nascimento Pinto, também conhecida como dona Santinha. Com a morte do fazendeiro, os índios acabam pagando pela terra a dona Santinha e, mais tarde, ao INCRA (LIMA, 2018).

Outro traço peculiar da aldeia Malacacheta pós-demarcação é a criação de bairros. Lideranças locais como Xaburu e Pimidy, o beija-flor wapichana, sugerem que a proximidade com centros urbanos tem ocasionado esse fenômeno geográfico de inserção de designações urbanas na organização espacial indígena. Como bairros são comunidades alojadas dentro de espaços maiores como as cidades, os Wapichana designam tais intraespaços de bairros, considerando o aglomerado de casas chamadas dap baukup ou kabayn baukup. Então, quando alguém diz "un dap kabaynhau yzikun iï, ou seja, "minha casa está no meio da aldeia", está falando de um bairro central.

$4 \mathrm{O}$ conceito de terras baixas não é consensual na etnografia, há quem o considere um recurso conceitual generalizador, 
A aldeia Malacacheta possui atualmente sete bairros mais a área central. As nominações dos bairros seguem uma lógica toponímica, ou seja, derivam de aspectos geográficos como já constatou Carneiro (2008). Segundo o levantamento que fizemos, são estes os designativos: Bacabal, assim designado por está situado em uma área com considerável densidade de bacabazeiro; Rabicho, cuja denominação é alusiva ao igarapé homônimo a ele adjacente; Gavião, por situar-se no perímetro próximo ao igarapé do Gavião; Jacaminzinho, assim chamado pela proximidade com o rio Jacamim; Jenipapo, cuja designação advém de um jenipapeiro que compõe um cinturão verde em torno do bairro; Lago do Pato, por situar-se em uma área lacustre de mesmo nome; e Mirixi, por ser uma região com grande densidade da referida vegetação.

\section{A noção de pessoa, pidian}

Para os Wapichana, a noção de pessoa (pidian) conflui para a seguinte percepção: os fluidos 5 e as substâncias ${ }^{6}$ corporais dos genitores, ao que parece, afiguram-se como o que antecede a existência da pessoa e a condição de possibilidade de formação do corpo; o corpo (nanaa) da criança pressupõe a pessoa em potência; a atribuição de um nome designativo ou de autodesignação sugere que a nominação pessoal wapichana acopla uma alma ao corpo, tornando-o uma pessoa; a maturação corporal leva o menino a se transformar em tuminary, processo que ocorre quando o rapaz engrossa o timbre da voz, fase apenas superada com o advento do casamento, segundo o qual o jovem se torna daionaora; ao gerar filhos e conduzi-los ao casamento, o homem ganha respeitabilidade perante a aldeia, todavia a idade plena só é alcançada com o nascimento dos netos, pois com tal fato o homem cumpre o ciclo geracional de ter sido filho, pai e, consequentemente, ter se tornado uma das figuras mais honradas entre os Wapichana, ou seja, avô (dukuz).

Eu nasci Ximensud, menino sem nome e fiquei assim até os dois anos. Menino não recebe nome quando nasce, o osso é muito fraco não aguenta. Depois recebi o nome de Kunaynyma'u, que significa bonito, era assim que minha mãe me chamava, esse nome trouxe alma ao meu corpo e se tornou a minha durunaa yy, alma-nome. Quando cresci, resolvi mudar de nome, agora sou Xaburu, que é uma bebida não fermentada feita de mandioca. Minha voz ficou grossa, eu já era um daionaora. (XABURU, 05/01/2018)

A tessitura da pessoa (pidian) para os Wapichana começa antes do nascimento de um corpo (nanaa). Se a criança nasce morta é apenas tratada como ma'chai e não se procede com a nominação pessoal e, mesmo que viva, a nomeação não é dada a princípio pelo peso ontológico que o nome pessoal porta, prática similar àquela adotada pelos Xavante (LOPES DA SILVA, 1986). A primeira implicação é a de que pelo fato do corpo ser uma categoria social e culturalmente construída ele remete às relações de substância, a exemplo do sangue (DAMATTA, 1976); e a segunda diz respeito aquilo que Gil (2003) ao estudar dois grupos pano, os Yawanawa e os Yaminawa, chamou de as possibilidades multivocais de modelagem do corpo através de diversos tipos de ações.

No caso da menina, desde a mais tenra idade, é chamada de zynaa, o que dura até o despontar dos seios, fase na qual ela passa a ser reconhecida como "menina moça”" ou kadyny. Por ocasião do primeiro fluxo menstrual, a menina torna-se kashinaru; no ápice da puberdade passa a ser reconhecida como moça

$5 \mathrm{O}$ sêmen do genitor.

${ }^{6} \mathrm{O}$ sangue dos genitores.

7 Informação repassada por Xaburu. 
ou mawys, por ser uma pessoa que ainda não enfrentou o parto. Com a chegada dos filhos, a designação correspondente a ela dependerá do lugar e do estado em que esteja em relação a quem designa, podendo ser mãe (daru) ou a variante mamãe (mamaa), mãe falecida (darun) ou sogra (imeyzu), sendo considerada uma adulta plena quando passa a ser avó (ku’ukun).

\begin{abstract}
Entrevistador: Você tem um nome pessoal wapichana? Se tem, qual é o seu nome? Zynaba: Eu tenho um nome de escola. Meu nome é Zynaba, mulher. Assim o senhor não vai entender! Deixe eu explicar: na escola a gente tinha que ter um nome wapichana e os professores e colegas começaram a me chamar de mulher.

Entrevistador: Mas por que mulher?

Zynaba: A mulher é forte, guerreira, enfrenta a luta diária de ser mãe, esposa e mulher, mas como eu já vivia junto com um rapaz eu não era como outra amiga que era chamada de Zynaba maydaiary'u, que é mulher solteira, eu era Zynaba mazidian, mulher casada. (18/03/2017)
\end{abstract}

A fala de Zynaba, moradora da aldeia Malacacheta, situada em Roraima, extremo-norte do Brasil, corrobora com a existência de um tipo específico de nome designativo pessoal entre os Wapichana, o nome de escola, e deixa evidente a mutabilidade dos nomes pessoais (pidiannau yy).

O nome designativo aciona imagens que a pessoa nominada reconhece em si, do contrário a nominação esvazia-se de sentido. A jovem se vê como forte (m'uzkan), guerreira (ba'iakaru) e explica o porquê da autoimagem: ela "enfrenta a luta diária de ser mãe, esposa e mulher”. A questão suscitada aqui diz respeito à projeção das nominações designativas nas relações sociais.

A avó de Pimidy, outro índio Wapichana, uma anciã de 95 anos, uma das pioneiras da aldeia Malacacheta ${ }^{8}$, alega que quando era criança ouviu falar da existência de nomes designativos indígenas, todavia, pela pressão exercida pelos missionários cristãos, jamais recebeu uma nominação indígena, o que não impediu os pais dela de usarem de criatividade dando-lhe um nome em português cujo significado é um monstro com língua de serpente - uma espécie de píton, tifão ou sucuri.

Segundo relatos colhidos em campo, até 1986, os nomes pessoais indígenas, embora não estejam totalmente ausentes da aldeia Malacacheta, parecem estar em uma espécie de limbo, sem que os moradores os usem em ambientes públicos, não passam de meros apelidos do mundo privado. É com a implantação do Centro Regional Indígena da Serra da Lua no ano de 1986 (PPP/EEISD, 2011) que a política de nominação reaparece em práticas educativas cujo protagonismo é capitaneado por professores de Língua Materna Wapichana.

Perguntado sobre nominações designativas, Xaburu assim relata:

Quando eu era criança lembro que todo mundo só chamava meu pai pelo nome wapichana dele, Mukau, que é a arma do branco, a espingarda. Os mais velhos só chamavam ele assim. Pra falar a verdade, eu só vim saber o nome dele de branco depois de grande. Já minha mãe eu num lembro se ela tinha nome wapichana, aliás, ter ela tinha, mas eu num lembro. Meu irmão até hoje a gente chama ele de Wizchip, que é mucuim. (04/12/2017)

O que segue agora é uma análise etnográfica de um conjunto de substâncias e atos da alma tidos pelos Wapichana como cruciais na fabricação do corpo e na tessitura da noção de pessoa. No primeiro momento, destacamos o sangue e a respiração e, no segundo momento, mostramos a modelagem da pessoa, pidian.

${ }^{8}$ Atualmente, a avó de Pimidy mora na região indígena do Surumu, município do Uiramutã, distante 279 km da capital Boa Vista. 


\title{
A tessitura da pessoa: a alma em ato
}

As pesquisas etnográficas entre os Wapichana, realizadas entre 2017 e 2018, trouxeram à baila a percepção de que os índios partem da ideia de que a alma (durunaa) efetua-se em atos. A fala e o sopro usados em processos de encantação compõem um exemplo de alma em ato: "Eu uso pori, ao chamar o vento. Eu assobio, como a minha avó ensinou. Como o vento é gente ele entende e vem" (Pimidy, 18/10/2017). Quando a durunaa se põe em ato dela advém uma força criadora e modificadora de realidades. O ponto fulcral é que o ato porta em si presença plena e não necessariamente memória: o tempo do ato é o presente e o ápice temporal no qual ele se desdobra é a enunciação, pois com a alma se impinge intervenção.

Para os Wapichana, o ser humano é visto sob o signo de três aspectos: o primeiro é udorona, uma espécie de princípio vital, cuja força tem o poder de animar e movimentar humanos e, em alguns casos, não humanos, sendo que ela se expressa de três maneiras, a saber, a respiração, os batimentos cardíacos e a fala. Além da fala, índice de diferenciação entre humanos e não humanos, udorona é manifesta pela sombra vigorosa do corpo projetada pelo sol; o segundo aspecto é udikini, contraface de udorona, haja vista que é a sombra pálida ou mais fraca que projetamos sob a luz solar; e terceiro ma'chai, o cadáver ou seu espectro quando se faz menção de seres humanos, ou mauka'u quando diz respeito ao corpo de não humanos.

\begin{abstract}
Xaburu: quando eu era criança sonhava em ser um tuminary, mas demorou e só quando minha voz engrossou e os outros menino falava, agora você é tuminary. $O$ tempo passou, agora eu sou um dukuz. Dukuz é bom, só é ruim não ser mais tuminary porque não tem mais a força de um tuminary pra caçar, pescar. Nanaa dói até se ando muito. (20/10/2018)
\end{abstract}

À primeira vista, presume-se que os Wapichana dão ênfase excessiva à idade, o que até certo ponto é compreensível, uma vez que as figuras mais valorizadas são os mais velhos (tynarynau). Contudo, a condição social de cada pessoa não passa pelo crivo da institucionalização, como afirma Farage (2002: 286), apenas "se reconhecem fases socialmente relevantes na trajetória de um indivíduo". Desse modo, não há entre os Wapichana nenhuma demarcação rígida e sistemática de ritos de passagem que assinalem mecanicamente a transição de uma fase para outra: por exemplo, por escolha pessoal, um homem pode ser reconhecido por toda vida pela autodesignação de solteiro (maydaiaru'u).

A criança wapichana ao nascer geralmente não recebe nenhum nome indígena ou de branco, pois os pais entendem que a pouca idade é justificativa suficiente para não se atribuir à criança algo com um peso ontológico demasiado, ou seja, um nome pessoal - pidian yy. Por um ano, o designativo familiar a ela endereçado é ximensud (termo nativo genérico para criança).

O nome, conforme fica sugerido, marca a pessoa como humana. A criança para ser nominada, na aldeia Malacacheta, requer alcançar um estado de ânimo compartilhado com o adulto, posto que a nominação designativa não pode derivar de uma sensação rarefeita e fugaz acerca do outro (o nominado), uma vez que para os Wapichana uma nominação pessoal recomendável é aquela que tem a possibilidade de se consolidar no decorrer do tempo, desse modo o desejo de nominação supõe uma compreensão razoável da natureza do nome a ser atribuído a terceiros. 
Na aldeia Malacacheta, os seres humanos são designados por nomes pessoais, não havendo indícios de formas patronímicas9. A nominação em si não parece envolver atos secretos. O único tabu, com peso ontológico, refere-se aos nomes dos mortos. Como os Wapichana creem que a maneira mais cômoda de lidar com a morte é pela via do esquecimento, a evitação quanto ao nome (yy) do espectro ( $m a$ 'chai) sugere uma forma de afastar possíveis embaraços na vida. Segundo Pimidy, a reação dos Wapichana ao ouvirem alguém, em geral brancos, pronunciarem os nomes de algum parente (paunaru) falecido, é a de indiferença, menos comum, e o riso (xazutan).

Conforme as palavras de Pimidy (04/12/2017), a aquisição de nomes pessoais "não é de qualquer jeito". Há nomes que podem designar características físicas de um indivíduo: Kawaru midiay'yziu (cavalo magro), Mis'u kakiwini’u (carapanã gordo); e há, também, designações que não apenas derivam de comportamentos, trejeitos do nominado, mas do estado de espírito que ele exibe diante da comunidade: Sukuku kunaikii (sabiá alegre), Tubuchi kibia’u (caju amargo), Kapaxi tu'uruba'u (tatu valente).

Ao dar um nome pessoal a alguém, o nominador estabelece um vínculo espiritual com o nominado da seguinte maneira: o nome é uma dádiva cuja existência depende de uma ativação, ou seja, o ato de atribuir-se um yy (nome) a alguém. Quando o nominador aciona um nome desencadeia um ciclo de obrigações morais, cabendo ao nominado receber a dádiva ofertada e retribuir tanto nominando pessoas da próxima geração quanto estreitando laços com o nominador.

\section{O sangue}

O compartilhamento de substâncias corporais ganha vigor entre os Wapichana mediante a doação de sangue dos genitores aos filhos no ato da concepção. Desse modo, um outro elemento que compõe o corpo e informa a pessoa é o sangue (izei). No pensamento wapichana, o sangue é um elemento que pode ser partilhado e transmitido de genitores para os filhos. Recebe-se de pai e mãe em porção igual: pai, mãe e filho formam um óribienao (muitos de mim), um coletivo para grupo familiar de uma pessoa (FARAGE, 1997: 84). Corrobora com tal perspectiva a fala de Atamyn: "o sangue é o laço que une as famílias, ele nos torna muitos, muito do meu dary [pai] em mim, muito de minha daru [mãe] em mim" (12/05/2017).

O sangue, em que pese ser uma substância natural corpórea, "apresenta notável rendimento simbólico nas cosmologias indígenas das terras baixas sul-americanas (TBAS), sobretudo pela sua importância nas concepções de pessoa [e] corpo" (VELDEN, 2007: 275). O líquido rubro é princípio vital entre os Wapichana, seu fluxo permanente assinala a presença da vida, dele procedem efusões simbólicas na manutenção do corpo. Velden (2007: 279) alerta que nas TBAS o que justifica a atenção dada ao sangue é a ideia de que nele há força para produzir o afastamento das doenças e, mais do que isso, ele supõe a busca pela saúde.

O estado do sangue verte-se em aparelho simbólico nas narrativas wapichana: na aldeia Malacacheta, uma "pessoa corada" presume-se ter sangue forte (izei mabuska’u) e "grosso" (midiu) e, logo, é saudável10. Só que a noção de sangue aqui diz menos da integridade física que da personalidade social - a preocupação em "engrossar o sangue" passa por técnicas presentes na memória coletiva

9 Nomes de sibs ou de linhagens que são aplicados individualmente a seus membros.

${ }^{10}$ Relatos repassados em 2016 por Xaburu e Nizuaba (tipiti fêmea) e confirmados em 2017 por Pimidy (beija-flor) 
e proclama costumes imperiosos que os Wapichana guardam com zelo, como beber suco de beterraba, consumir caldo de feijão e ingerir vinho de açaí. O foco é mais com a construção social da pessoa do que com disfunções hormonais ou deficiências imunológicas, o que faz lembrar a sábia afirmação de Lévi-Strauss (2000: 193): "A integridade física não resiste à dissolução da personalidade social".

Nas redes de discursos wapichana, o sangue aloja-se nas malhas mais intrínsecas dos regimes de conhecimento. Segundo Viveiros de Castro (1996: 1), as construções nativas sobre o sangue forjam uma discussão sobre "o corpo humano: sua fabricação, comunicação com o exterior, as regras que o incorporam a sociedade e o transformam em símbolo”. Na aldeia Malacacheta, as narrativas sobre o sangue são intencionais e periódicas. "Sangue, lembremos, é porção partilhada da alma, e constitui o vínculo entre o recém-nascido e seus pais" (FARAGE, 1997: 239). O momento inicial da tarefa de produção da pessoa presume a doação de sangue dos genitores, o que requer a conjugação de corpos e a permuta de fluídos corporais para consolidar o ato geracional.

Conforme Viveiros de Castro (1996), o social não se deposita sobre o corpo como matéria amorfa, pelo contrário ele cria o corpo. Na aldeia Malacacheta, a fabricação do corpo (nanaa) supõe uma intervenção consciente sobre a matéria. O que se fabrica é o ser humano, a pessoa (pidian) na acepção nativa do termo: o estatuto da pessoa constrói-se pelo ato inaugural de doação de sêmen e sangue dos genitores e deles se esculpe um ser vivente no ventre materno, ainda que desprovido da essencialidade humana ou sem atributos propriamente humanos, como respiração e fala.

$\mathrm{Na}$ ótica wapichana, o sangue assinala três índices na formação e deformação da pessoa no ciclo vital: o acesso à vida, uma vez que só é possível viver porque o sangue se ramifica no corpo por redes capilares, ou como dizem os nativos, ele "irriga o corpo 11 " (metáfora tão ao gosto Wapichana); a capacidade de reprodução, que implica retribuir à dádiva do sangue recebido, doando vida a um novo ser; e o fim da vida, quando o sangue cessa o curso de sua correnteza, perde a capacidade de fluxo e, por força da morte, apodrece, tornando-se uma seiva viscosa de coágulos. Na cosmologia wapichana, o sangue é objeto de cobiça dos $k a-$ nokushi, seres que vivem em aldeias, na mata e nas serras, cujos calcanhares são deformados (voltados para a frente). Como morcegos, perambulam à noite pelas matas densas com "o desejo de sugarem sangue de crianças", conforme relata Xaburu (02/03/2017). A fabricação primordial dos humanos, ainda conforme a cosmologia wapichana, é produto da ação do demiurgo Tuminkaru (FARAGE, 1997), ele não apenas cria, como enche os corpos humanos de um líquido, izei wyza'u (sangue vermelho).

Na perspectiva cosmológica nativa, a ação do mito opera como um dispositivo de explicação de como se fabrica e se recria a condição humana. Segundo López (2006: 359), as ações humanas pressupõem planos de manejo de formação e transformação do "espaço-temporal concreto". A aldeia Malacacheta verte-se em espaço societário onde são moldadas as corporalidades wapichana e se recriam práticas histórico-sociológicas. Conforme Velden (2007: 279), "o sangue se perde, irremediavelmente, no curso da vida, por meio de ferimentos, nas dores do trabalho cotidiano, no parto e nas regras mensais das mulheres", e os Wapichana ao que parece não ignoram tal percepção: para eles, a perda de sangue fra- 
giliza o corpo e denuncia o vigor combalido do corpo. O rosto empalidecido é considerado como um sinal de um corpo abatido ou doente, de modo que a pessoa, nessa condição, é tratada como aiberu (pálida).

A percepção que os Wapichana têm acerca do sangue, guardadas as devidas proporções de espaço, tempo e costumes, assemelha-se àquela que López (2006: 359) constatou ao realizar pesquisas etnográficas sobre corporalidade e pessoa entre os Jodï venezuelanos: um acontecimento aparentemente fixo, como o derramamento de sangue, seja por um eventual ferimento em espinhos ou uma arranhadura provocada por garras de não humanos, ou até mesmo o sangue que jorra durante o abate de uma caça, conecta-se exponencialmente "à reprodução de eventos cosmológicos", os quais seguem por gerações.

A interpretação nativa para a cosmologia do sangue aponta, assim, para uma percepção de que o mito se concretiza e se atualiza no cotidiano, uma vez que o sangue não é apenas aquilo que se apresenta de modo visível aos olhos, mas ele pressupõe a vitalidade do sistema circulatório presente no corpo, cujo líquido vermelho e viscoso irriga desde os vasos capilares, passando por veias e artérias e cumprindo um perene retorno ao coração (nhykynyy) - sinônimo de vida na Malacacheta.

Por seu turno, as doenças têm a capacidade de deformar as pessoas ao afinarem o sangue: izei dysasaba’u (sangue fino) é uma forma de nominar uma pessoa convalescente ${ }^{12}$. Presume-se que o sangue se transmuta em água, em particular suor e saliva, sobretudo em face de doença brava (kaziwkari tu'uran), como malária ou tuberculose. $\mathrm{O}$ sangue não espesso representa ameaça à integridade da pessoa, já que é um prenúncio de morte próxima, assim creem os nativos na aldeia Malacacheta.

Os Wapichana nutrem a crença de que o sangue perdido por uma pessoa nos incontáveis acidentes da vida, nos ferimentos que laceraram a pele e nos partos deve ser recuperado. Eis algumas maneiras: a alimentação, com especial ingestão de fígado ou carne de peixe, feijão e beterraba; as alegrias do espírito com jogos, pescarias, banhos em rios e igarapés; e os processos xamânicos de cura. Com o derramamento de sangue, o vigor humano desfalece, o corpo declina em franca ruína, as pálpebras ficam turvas, os joelhos vacilantes, as pegadas débeis e a pessoa entra em um labirinto perigoso cujo desfecho pode ser a morte iminente ${ }^{13}$.

A reposição sanguínea pereniza a reconstrução da pessoa. É como se ela fosse arrancada de um vale de sombras e fraquezas na qual sucumbia, sendo reposta no mundo social da força (ma'uskan) e da coragem (ka’itian), virtudes morais de alta estima na aldeia Malacacheta. O ritmo das porções de sangue perdido e recuperado dá a tônica da vida wapichana reabilitada.

Não há como se perder de vista que o sangue se desloca segundo a força vital de um músculo propulsor cuja ação tem significação social para os wapichana: o coração (nhikynyy). Como o que interessa aqui é a produção da noção social de pessoa, dois aspectos são ressaltáveis nele: os batimentos cardíacos (sinais de manifestação de udorona) e a noção de sede dos sentimentos. Os batimentos cardíacos assinalam na cosmologia wapichana o compasso da vida em movimento, indicam também o palpitar da alma em sua jornada entre os vivos ${ }^{14}$; como repositório de sentimentos, quando os Wapichana fazem menção dele é para expressar o estado de espírito das pessoas: "Ungary nhikynyy kaxa’uran" ou "meu coração está triste" (OLIVEIRA; SILVA; SILVA; 2013: 150).

12 Informações repassadas por Xaburu, em 2017.

${ }^{13}$ Conforme informações repassadas pela wapichana Lindia da Silva Pereira ou Mamiaba (nambu fêmea).

${ }^{14}$ Informações obtidas através de Xaburu e Pimidy. 


\section{A respiração}

Outra expressão consistente de udorona é a respiração e tal imagem não se restringe apenas a um processo fisiológico, aeróbico e mecânico de inflar os pulmões com ar, absorvendo oxigênio e eliminando dióxido de carbono, mas, sobretudo, diz respeito à fala articulada. Nesse sentido, os Wapichana presumem que crianças pequenas que ainda não falam não possuem udorona. Como o princípio vital é traço característico dos vivos não há porque se cogitar que os mortos o possuam. Segundo Farage (1997: 289), só resta aos espectros "um murmúrio rouco e ininteligível”.

A respiração supõe o limiar entre a vida e a morte e no período pré-natal da gestante é a certeza de que ainda não há alma no ventre, já que na placenta onde a criança se aloja não há a respiração no sentido de aspirar, de encher de ar os pulmões. "A respiração acompanha o valor da fala, questão que se apreende com maior nitidez no contexto da magia: soprar e falar são atos homólogos, que surtem o mesmo efeito encantatório, por serem ambos alma" (FARAGE, 1997: 84). Na construção social da pessoa, a alma apresenta uma dupla composição: fala e sopro (ou respiração). A fala articulada resulta do processo de maturação corporal e intelectual como já foi dito; a respiração é uma qualidade inerente ao corpo.

Segundo Xaburu, um dos mais respeitados kwad pazu (historiadores da aldeia), não é de se estranhar que a ruína do corpo, isto é, deixar de respirar em definitivo sugere a cessação da alma, a pessoa transforma-se em "ma'chai, o cadáver e seu espectro" (23/05/2017). Convém ressaltar que, na cosmogonia wapichana, os demiurgos criadores e transformadores Tuminkaru e Duid se foram definitivamente com a queda da "grande árvore" e, independente do plano supranatural que possam estar, não intervêm mais nas relações humanas (LIMA, 2018). Se o corpo cessa de respirar por falência múltipla e não por eventuais desmaios, a alma terá partido. E nenhuma elaboração refinada sobre o que sucede após a morte compõe a visão nativa, tudo se resume apenas na afirmação: "ninguém sabe para onde vai udorona" (XABURU, 02/05/2017). Subjaz nessa afirmação a presunção proposta por Benjamin (2010: 208) de que "a morte é a sanção de tudo o que o narrador pode contar”. Excetuam-se dessa sentença os xamãs que, no pós-morte, assentam moradia em uma árvore chamada Toronai, situada no topo das serras ou no céu.

\section{Modelagens da pessoa}

Como já foi dito anteriormente, os Wapichana creem na possibilidade de modelagem do corpo através de diversos tipos de ações. Assim, concebem que as crianças, kuraiziannau, são corpos a serem moldados com o buril da maturidade, sendo os nomes designativos uma das primeiras formas de esmerar o corpo no processo de construção da pessoa. O sistema de nominação wapichana faz lembrar aquilo que Mauss (2003 [1938]: 200) chamou de "vínculo de almas", pois na aldeia Malacacheta acredita-se que a nominação vincula nominador e nominado, uma vez que um nome designativo tem uma alma a ser acoplada no corpo do nominado, algo que tratarei com mais esmero quando trouxer para a discussão a noção do segundo corpo professada pelos Wapichana.

O segundo aspecto que gostaríamos de comentar sobre a construção do corpo entre os Wapichana é específico do campo das ações, que modelam o corpo segundo um ideal que toma qualidades e capacidades valorizadas culturalmente na 
aldeia Malacacheta e que um adulto, segundo os nativos, deve possuir sob pena de sofrer vergonha moral diante da comunidade. Segundo escritos de Viveiros de Castro (1996: 128), o corpo nas TBAS não é pensado apenas segundo um ponto de vista fisiológico, mas como "um conjunto de afecções ou modos de ser que constituem um habitus". Trata-se de uma prática comum nas terras amazônicas, cuja ideia é manipular os corpos com a finalidade de socializá-los: basta lembrar os rituais de modelagem dos corpos das crianças, como os mariwin entre os Matis ${ }^{15}$ (ERIKSON, 1996). Tal ritual consiste na evocação de ancestrais cujo papel é bater nas crianças com chicotes feitos de talo de palmeira com o propósito de endurecê-las, tornando-as mais vigorosas.

É claro que os Wapichana não possuem rituais semelhantes aos Matis, no que diz respeito ao fortalecimento do corpo. Todavia, compartilham de práticas culturais que servem de critérios para a obtenção de características, se não ideias, pelo menos desejáveis que o corpo deve ter, as quais se resumem no conceito de força (ma'uzkan). As qualidades vinculadas ao referido conceito comportam mais comportamentos éticos do que capacidades fisiológicas, pois presumem disposição para o trabalho (kaydinhaa'u) e coragem (ka’itian) de enfrentar os inúmeros percalços que a vida impõe. Assim, uma pessoa que demonstra preguiça ou má vontade de participar de trabalhos coletivos (os ajuris), assume perante a comunidade uma reputação oposta àquela propiciada por ma'uzkan, que é a de preguiçoso (zunziu). Descola (1998) mostra que, na maioria dos povos indígenas amazônicos, a condenação à avareza constitui um princípio moral, desse modo, a preguiça supõe uma forma de desvirtuar o corpo à medida que ela pode ser interpretada como um ato mesquinho com o próprio corpo, tendo em vista que priva a pessoa da capacidade produtiva em favor do coletivo. Entre os Wapichana, um zunziu também pode ser aquela pessoa que não vai à caça, logo não tem carne para repartir com os demais, mas que não se furta a receber a carne obtida pela caça de outras pessoas sem que se comprometa com qualquer contrapartida. Em ambos os casos, o que está em jogo são as relações interpessoais. Segundo Xaburu, uma forma de uma pessoa alcançar a aprovação de um futuro sogro (imedukuz) é demonstrando capacidade e coragem para trabalhar, provendo peixe (kupay), lenha (zuaakari) e carne (dynai). Para os Wapichana, ajudar (kaminkia’ytan) é um signo de respeito que traz sobre o praticante a boa reputação.

É, pois, com udorona (principio vital) que se nomina uma criança, tornandoa uma pessoa (pidian). Com o corpo (nanaa), a criança produz os primeiros sons disformes e ininteligíveis, ele é o veículo que conduz os primeiros passos titubeantes e inseguros sob os olhares afetuosos e embevecidos de pais, avós ou demais familiares; por ele vertem-se as primeiras lágrimas, ressoam choros, expelem-se dejetos, afloram-se os sentidos e o mundo externo delineia-se em contornos atrativos. Mas o corpo é também atividade, lúdica ou laboriosa, constrói, forma, deforma, reforma e transforma, com ele se nomina e se é nominado. Falar em sistema de nominação pessoal requer o reconhecimento de que se trata de um sistema terminológico que remonta a uma forma simbólica de definição da pessoa.

O corpo, segundo DaMatta, Seeger e Viveiros de Castro (1979: 13), é "afirmado ou negado, pintado e perfurado, resguardado ou devorado, tende sempre a ocupar uma posição central na visão que as sociedades indígenas têm da natureza do ser humano". Ele é nominado e assume a capacidade de nominar. Nominações podem ser entendidas como "tentativas particulares de pessoas particulares de colocar essas coisas em alguma espécie de estrutura compreensiva e significativa”

${ }^{15}$ Povo de língua Pano que habita o sudoeste do estado brasileiro do Amazonas, em particular na Terra Indígena Vale do Javari situada na região do alto Solimões. 
(GEERTZ, 1989: 21). Na aldeia Malacacheta, nominações supõem convenções coletivas da vida social wapichana. A construção da noção de pessoa passa pela dualidade, como sugere Viveiros de Castro (1996): indivíduo é personagem, devir e ser, corpo e alma. O próprio corpo é atravessado por um caráter dual, haja vista que nele operam aspectos internos que vão desde a reprodução física, a habilidade motora, até a capacidade sensorial e, também, aspectos externos ligados ao nome designativo ou de autodesignação que porta, aos papéis públicos que exerce, aos ritos cerimoniais que comunga e partilha, ou seja, o mundo social no qual interage, o qual é expresso na pintura, na ornamentação corporal, nas danças e canções.

\footnotetext{
Um sentido comum às várias abordagens antropológicas sobre o corpo - por diferentes e às vezes antagônicas que possam ser - é o de pensar o corpo como uma construção social e cultural, e não como um dado natural. A antropologia busca desnaturalizar o que é visto como dado pela natureza - seja isso uma regra de comportamento e de classificação social [...], seja a própria noção de corpo - e mostrar as dimensões sociais e simbólicas desses fenômenos. (MALUF, 2001: 88)
}

Ressaltamos, todavia, que os Wapichana nem de longe são reféns da visão utilitarista a que o termo corpo possa eventualmente a remeter, mesmo em que pese portarem resquícios de uma visão dualista que dicotomiza ser e corpo, no sentido de possuírem um nome-alma (yy) e terem corpo (nanaa). Na aldeia Malacacheta, hábitos, costumes e crenças diluem-se em um processo de incorporação.

Nominar o corpo para os Wapichana, ao que parece, é um ato social e cultural, cuja subjetividade pode ser reflexiva e ansiosa. Geertz (1989) define como subjetividade reflexiva aquela que supõe discursos e práticas que se erigem por meio de atitudes culturais - o ato de nomeação em si é um exemplo - ; por seu turno, uma subjetividade ansiosa pode ser aquela que se constrói por meio de ações públicas que geram ansiedades como no caso do processo simbólico de nomeação de uma pessoa, uma vez que o nome a ser portado tende, via de regra, a acompanhar o donatário por toda a extensão da vida (exceto se perder o sentido cosmológico correspondente ou for trocado por outro que a pessoa sinta-se melhor designada por ele), o que faz do nome pessoal um símbolo socialmente significante.

\begin{abstract}
Antes eu tinha outro nome colocado pelos meus amigos, mas eu não gostava. Meu nome era mamão (Ma'apai). Diziam que eu era mole. Eu não achava que meu nome era mamão, pra mim aquilo era apelido e eu num gostava. Como os meninos sabiam que eu tinha raiva, então chamavam. Quando eu já era professor, uma amiga disse que eu parecia mais com Tapi`z, era grande, forte e trabalhador. Eu gostei, desse nome eu gosto e pegou, todo mundo me chama assim. (TAPI'IZ, 13/10/2017)
\end{abstract}

A experiência de autodesignação supõe a elaboração de um mundo comum de significados sociais e culturais partilhados por uma sociedade. Ainda que um ato de nominação pessoal pareça um gesto natural e dado, fica a advertência de Mauss (2003 [1938]) como reflexão: os gestos são fabricados por normas coletivas, por convenções culturais. Segundo Maluf (2001: 93), o corpo é "um conjunto de atitudes, de afecções, de modos de ser, de habitus". Corpos, gestos, "habitus", nomes são, antes de tudo, construções sociais que se impõem aos indivíduos, pessoalizando-os em conformidade com a vontade geral do grupo.

Para os Wapichana, as oposições polares (corpo e alma, natureza e cultura) não supõem algo estático ou mera relação de complementaridade. Para eles, é 
possível nominar não humanos de Chamchamuri ${ }^{16}$ (Pai de todas as onças) e dar nome de onça, Baydukury, aos humanos. Os nomes designativos e de autodesignação assemelham-se a atos de diferenciação consciente que se sobrepõem a um fundo de similaridade comum, que é a alma, singularizando uma pessoa frente às demais.

Na conformação da pessoa, os Wapichana concebem que um adulto pleno pode vir a ser, além de um avó e sogro, um kwad pazo (historiador da comunidade). A implicação é que o conhecimento sugere, assim, um processo cumulativo. Segundo Farage (1997: 219), "o kwad pazo é um sábio, e a sabedoria, para os Wapishana, é um derivativo necessário da experiência de vida”. Os kwad pazo usam também uma nominação autodesignativa de caráter jocoso, restos de $k u-$ tyainha'u (antigos). Há dois motivos para isso: primeiro, eles são narradores das histórias de si e de terceiros; segundo, participaram de um passado cuja memória os mais jovens não partilham. Hartmann (2007: 101) afirma que "enquanto narram e mostram a si mesmos, os contadores promovem uma reflexão coletiva sobre [...] processos de crise e de transformação”. No caso dos kwad pazo, a tensão das narrativas alcança o ápice com histórias sobre viagens e relatos sobre acontecimentos míticos.

Sobre o kwad pazo há duas possibilidades de entendimento da tradução da palavra: pode ser equivalente a historiador e, nessa acepção, subjaz o sentido de pessoa com faculdade intelectiva de contar histórias dos tempos dos avós, demonstrando uma vasta memória e uma lembrança esmerada em detalhes narrativos, que tendem a fazer o ouvinte visualizar o que está sendo narrado como se ali estivesse presente; pode ser, também, sinônimo de narrador, em sentido benjaminiano, ou seja, aquele cuja arte narrativa assenta-se no "extraordinário e miraculoso" - que praticamente "não explica nada", mas, ao narrar, tem a capacidade de "suscitar espanto e reflexão" e evocar a força germinativa da memória (BENJAMIN, 2010: 204). Outrossim, como afirma Hartmann (2007: 106-7), "o reconhecimento do contador como sujeito dá direito a um nome que não necessariamente é o mesmo nome de batismo e acaba se dando sempre no retorno à sua rede de relações original - sua comunidade narrativa”.

\section{Considerações finais}

Corpo, palavra e nomes designativos e autodesignativos informam a pessoa na aldeia Malacacheta: nanaa traduz a manifestação externa da construção da pessoa, haja vista que é o corpo tonificado, pintado, assinalado com ornamentos e, sobretudo, nomeado; a palavra sugere uma ação simbólica imbricada no processo de nominação do corpo (nanaa), o que resulta na construção social da noção de pessoa (pidian); o nome pessoal, por sua vez, funda a ideia de uma almanome que se acopla ao corpo.

Portar um nome (yy) wapichana, seja designativo ou de autodesignação, implica uma forma de pessoalização do sujeito. A se nominar, em outras palavras, fabricam-se corpos e, de modo reverso, quando corpos são fabricados ocorre de fato o processo de nominação pessoal.

$\mathrm{Na}$ aldeia Malacacheta, quando se nomina um indivíduo, especula-se o início da projeção social da pessoa. Um nome designativo ou autodesignativo wapichana imprime uma marca social sobre a pessoa, ao torná-la reconhecível entre

\footnotetext{
${ }^{16}$ Se a referência for mitológica equivale a Pai de todas as onças, como na expressão "Chamchamuri kiupan kanuku diizk" (o pai de todas as onças está voltando do mato) (OLIVEIRA, SILVA e SILVA, 2013: 210). Se for um nome designativo ou autodesignativo é traduzido como gato maracajá.
} 
os Wapichana. Um nome pessoal wapichana evoca um signo de distintividade, algo similar às pinturas corporais.

Recebido em 23 de julho de 2019.

Aprovado em 29 de novembro de 2019.

\section{Referências}

ANDRELLO, Geraldo. Cidade do índio: transformações e cotidiano em Iauaretê. São Paulo: Ed. UNESP, 2006.

ANDRELLO, Geraldo. Falas, objetos e corpos: Autores indígenas no alto rio Negro. Revista Brasileira de Ciências Sociais, 25 (73): 5-26, 2010.

BENJAMIN, Walter. Obras escolhidas: magia e técnica, arte e política. São Paulo: Brasiliense, 2010.

CARNEIRO, João Paulo Jeannine Andrade. A morada dos Wapixana: atlas toponímico da região da Serra da Lua (RR). 189p. Dissertação (Mestrado em Linguística), Universidade de São Paulo, 2008.

CAVALCANTI-SCHIEL, Ricardo. Para além de terras altas e terras baixas: modelos e tipologias na etnologia sul-americana. Revista de Antropologia (USP), 57 (2): 251-290, 2014.

DAMATTA, Roberto. Um mundo dividido: estrutura social dos índios Apinayé. Petrópolis: Vozes, 1976.

DAMATTA, R.; VIVEIROS DE CASTRO, E.; SEEGER, A. A construção da pessoa nas sociedades indígenas brasileiras. Boletim do Museu Nacional, 32: 2-19, 1979 .

DESCOLA, Philippe. Estrutura ou sentimento: a relação com o animal na Amazônia. Mana, 4 (1) : 23-45, 1998.

ERIKSON, Philippe. La Griffe des Aieux. Marquage du corps et démarquage ethnique chez les Matis d' Amazonie. Paris: Editions Peeters, 1996.

FARAGE, Nádia. As flores da fala: práticas retóricas entre os Wapishana. Tese (Doutorado em Literaturas de Língua Portuguesa), Universidade de São Paulo, 1997.

FARAGE, Nádia. "Instruções para o presente: os brancos em práticas retóricas Wapishana” (Capítulo 17). In: ALBERT, B.; RAMOS, A. R. (orgs.). Pacificando o Branco: cosmologias do contato no Norte-Amazônico. São Paulo: Editora UNESP/Imprensa Oficial do Estado, 2002. pp. 507-531.

GEERTZ, Clifford. A interpretação das culturas. Rio de Janeiro: Zahar, 1989. 
HUGH-JONES, Christine. Social organization among South American Indians of the Vaupés Area of Colombia. Cambridge, PHD dissertation, University of Cambridge, 1977.

LÉVI-STRAUSS, Claude. As Estruturas Elementares do Parentesco. 2. ed. Tradução de Mariano Ferreira. Petrópolis: Vozes, 1982.

LIMA, Fabio de Sousa Lima. Formas de nominação pessoal wapichana na aldeia Malacacheta. Dissertação (Mestrado em Antropologia Social), Universidade Federal de Roraima, 2018.

LÓPEZ, Egleé. Noções de corporalidade e pessoa entre os jodï. Mana, 12 (2): 359-388, 2006.

MALUF, Sônia Weidner. Corpo e corporalidade nas culturas contemporâneas: abordagens antropológicas. Revista Esboços, 9 (9): 87-101, 2001.

MAUSS, Marcel. Sociologia e Antropologia. São Paulo: Cosac Naify, 2003 [1938].

MCCALLUM, Cecilia. Aquisição de gênero e habilidades produtivas: o caso Kaxinawá. Estudos Feministas, 7 (1-2): 157-175, 1999.

OLIVEIRA, Odamir; SILVA, Bazilio da; SILVA, Nilzimara de Souza. Paradakary urudnaa: dicionário Wapichana/português, português/Wapichana. Boa Vista: EDUFRR, 2013.

PROJETO POLÍTICO PEDAGÓGICO. Centro de Formação Wapichana: Escola Estadual Indígena Sizenando Diniz, aldeia Malacacheta (RR), 2011.

VELDEN, Felipe Ferreira Vander. Circuitos de sangue: corpo, pessoa e sociabilidade Karitiana. Revista Habitus, 5 (2): 275-300, 2007.

VIVEIROS DE CASTRO, Eduardo. Os pronomes cosmológicos e perspectivismo ameríndio. Mana, 2 (2): 115-144, 1996. 


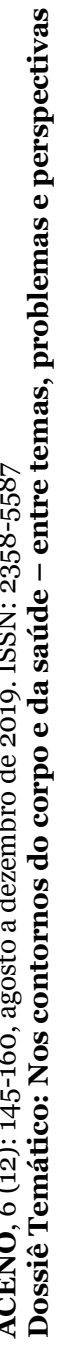

160 